Journal of Engineering and Science Research 5 (3): 01-06, 2021

e-ISSN: 2289-7127

(C) RMP Publications, 2021

DOI: $10.26666 /$ rmp.jesr.2021.3.1

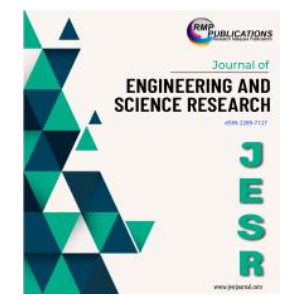

\title{
Tri-Wheels Stair Climbing Trolley
}

\author{
Muhammad Syafiq Bin Norain and Yew Been Seok \\ Faculty of Innovative Design and Technology, Universiti Sultan Zainal Abidin, Malaysia.
}

\begin{abstract}
Buildings with no lift and escalator facilities make it difficult for users to lift heavy loads from the ground floor to the upper floor. Human labor is the solution. There is a need to develop a mechanism that can lift loads while traveling through stairs to reduce the ergonomic constraint that may lead to the risk of developing musculoskeletal disorders (MSD). This work presents the tri-wheels stair climbing trolley for this purpose. The triwheels stair climbing trolley consists of two pairs of quasi-planetary wheel frames to hold three wheels at both sides, a frame, a movable base, and a manual hand winch. The trolley frame is made from malleable hollow steel, and mild steel is used for the wheel frames due to its high strength and toughness. Physical testing was done on the designed trolley, and it was found that it can carry the maximum load, which is $20 \mathrm{~kg}$, and tri-wheels design can climb the stair up and down smoothly without causing damage to the trolley and stair.
\end{abstract}

Key words: stairs climbing, trolley, tri-wheels, quasi-planetary wheel frame

\section{INTRODUCTION}

A trolley that can lift loads while climbing up the stairs is beneficial for users that live in apartments or flats. A hand trolley can be used to transport heavy loads from one place to another. It plays a vital role in lifting loads [2].

A hand trolley usually consists of two wheels located and has two handles on its support frame. These handles are used to push and pull the device [3]. The handles may reach out from the top back of the edge, or one handle may bend from the back, and it stands upright in an L-shape. Besides, products will stack on the platform, and it is tilted backward to balance the platform and the support frame. Various trolleys from steel, aluminum, and durable plastic are readily available in the current market [4].

For stair climbing purposes trolley, this type of trolley is commonly built with six wheels, and mild steel is used, which is suitable for carrying moderate loads. For buildings that do not have elevators or escalators, a six wheels trolley may ease people to load and unload heavy items quickly. The trolley has a manual hand winch at the port of load items, people will easily lift the items from the ground up to the table or something higher than the trolley so that back pain or musculoskeletal disorder problems can be reduced. Figure 1 shows the movement of the stair wheel trolley on steps [5].

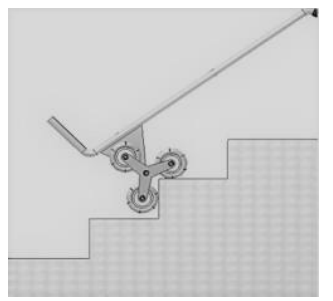

Figure 1: Movement on stairs [5]

In this work, a tri-wheel stair climbing trolley is proposed. It serves as a mechanism for easy transportation of loads over the stair. The trolley is beneficial for users that live in buildings that do not have elevator and escalator facilities to lift heavy loads. Large and heavy loads can be transferred with less human effort and can protect people from having back injury and other health problems that contribute to the risk of developing musculoskeletal disorders (MSD), resulting from lifting and carrying heavy loads when climbing stairs from the bottom floor to the top floor. This trolley has a moveable load base to ease the user for lifting the loads.

Corresponding Author: Yew Been Seok, Faculty of Innovative Design and Technology, Universiti Sultan Zainal Abidin, Malaysia, bseokyew@unisza.edu.my 


\section{EXPERIMENT METHODOLOGY}

\section{D Modeling}

The tri-wheels stair climbing trolley was designed in Autodesk Inventor software to determine the external dimensions. It consists of two pairs of Tri-Star wheel frames to hold six wheels at both sides, nuts, and bolts. The length of the trolley is $101 \mathrm{~cm}$. The height is 60.5 $\mathrm{cm}$. The quasi-planetary wheel frame design was used [5] as shown in Figure 2. The diameter of the quasiplanetary wheel frame is $22.5 \mathrm{~cm}$. The diameter of each wheel is $10.16 \mathrm{~cm}$. The distance between the two-wheel frames is $49 \mathrm{~cm}$. It has a manual hand winch with a load capacity of $5 \mathrm{~kg}$ until $25 \mathrm{~kg}$. The design of the trolley body is shown in Figures 2 and 3, respectively.

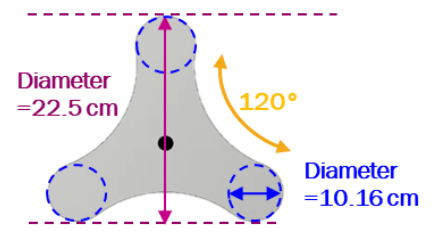

Figure 2: Quasi-planetary tri-star wheel frame

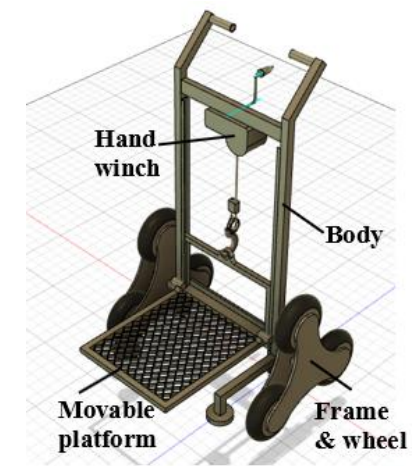

Figure 3: 3D design of the stair climbing trolley

\section{Material Selection and Fabrication}

A quasi-planetary wheel frame design was selected as it is easy to shape, drill, and cut. The wheel frame was used to hold the wheels together. The diameter of the wheel frame is $22.5 \mathrm{~cm}$, which exerts stability and strength to the wheels with $120^{\circ}$ angle between two-wheel axes for smooth functioning. A mild steel plate was selected with high strength, toughness, ductility, and no special tools are required for manufacturing [6].

The material for the wheel was selected based on the coefficient of friction between the floor surfaces and wheels. The material selected for the wheels is a filled rubber tire as the rubber is good friction and shock absorber. The diameter of each wheel is $10.16 \mathrm{~cm}$, see Figure 4(b). Wheels and quasi-planetary wheel frames are assembled as shown in Figure 4(c).
For lifting purposes, A manual hand winch is selected as a tool to lift loads, refer to Figure 4 (d) [7]. It has a brake to ensure the load remains suspended when the crank is released. This device uses a cable for lifting capacity ranging from $8 \mathrm{~kg}$ to $25 \mathrm{~kg}$.

For ease of manufacture purpose, Hollow mild steel was selected as the material for the trolley body (easy to cut, shape, and joint together). Moreover, it is cheap and malleable. Mild steel has low tensile strength with $7850 \mathrm{~kg} / \mathrm{cm}^{3}$ density [5]. The components or parts of the trolley body were joined together with Gas metal arc welding (GMAW) [8], which is also known as MIG (inert metal gas). The final assembly is shown in Figure 4(e) and Figure 4(f) for final finishing.

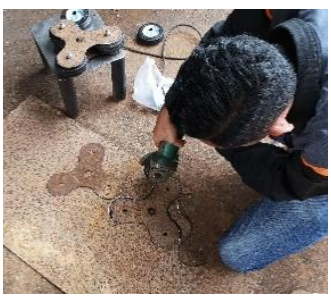

(a)

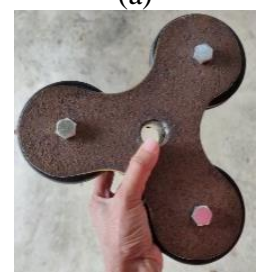

(c)

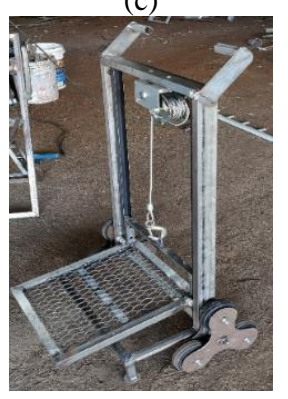

(e)

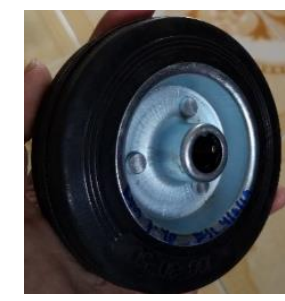

(b)

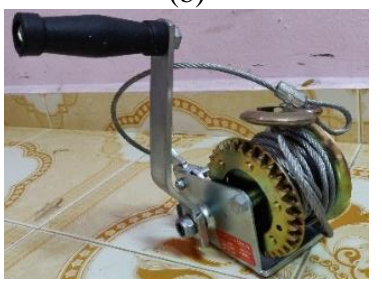

(d)

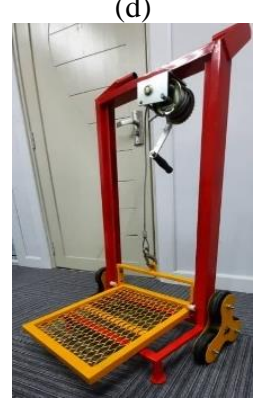

(f)
Figure 4: Fabrication and assembly of tri-wheels stair climbing trolley

\section{RESULTS AND DISCUSSION}

\section{Finite Element Analysis}

The finite element analysis (FEA) on the structural component of the tri-wheels stair climbing trolley was performed by using Autodesk Fusion 360 software to evaluate the stress and displacement. FEA analyzes the limitation of the trolley and identifies whether it is safe to lift loads or not. The volume and mass of the designed 
trolley were analyzed with respect to the type of material used in the designed trolley. The FEA analysis focused on the crucial parts of the designed trolley, namely the movable platform, body, frame and wheels, and hand winch. Four parameters were analyzed, namely Von Mises stress, displacement, equivalent strain, and safety factor.

From the simulation analysis, it was tested that the volume and the mass of the trolley are $2.707 \times 107$ $\mathrm{mm} 3$ and $468.555 \mathrm{lb}$ mass, respectively, which reflects the standard mass and volume of the mild steel, that is the proposed material for the designed tri-wheels stair climbing trolley.

\section{(i) Von Mises Stress}

Von Mises stress is a maximum stress theory that analyze on product failure, particularly for ductile materials like steel [9]. Von mises stress must be greater than 1 for the design to be acceptable. For steel, the standard mild steel yield stress is $247 \mathrm{MPa}$ and ultimate tensile strength is $841 \mathrm{MPa}$. The component of the designed trolley must exert Von Mises stress within the standard mild steel yield stress and ultimate tensile strength when loads of $20 \mathrm{~kg}$ are exerted on the movable platform, to ensure that there is no fracture and breaking problem will be experiencing on the components.

The maximum Von Misses Stress of the movable platform, the body, frame, and wheel, and hand winch is $26.652 \mathrm{MPa}, 4.069 \mathrm{MPa}, 0.026 \mathrm{MPa}$, and 42.14 $\mathrm{MPa}$, respectively, as tabulated in Table 2. This value reflects the highest bending moment which occurs at the widest point. It was tested that the value of the stress obtained for the components of the designed trolley is within the standard mild steel Yield Stress (247 MPa) and ultimate Tensile Strength (841 MPa). This indicates that the designed trolley will not experience fracture and breaks when loads of $20 \mathrm{~kg}$ are exerted on the designed trolley. The components of the designed trolley were within the safe limit, as observed from the simulation analysis that blue contour was applied on each trolley and no negative error or red region was detected, see Figure 5.

Table 1: Von Mises stress on the components of tri-wheels stair climbing trolley

\begin{tabular}{|c|c|}
\hline Components & Stress-Von Mises (MPa) \\
\hline Movable platform & 26.652 \\
\hline Body & 4.069 \\
\hline Frame \& wheel & 0.026 \\
\hline Hand winch & 42.14 \\
\hline
\end{tabular}

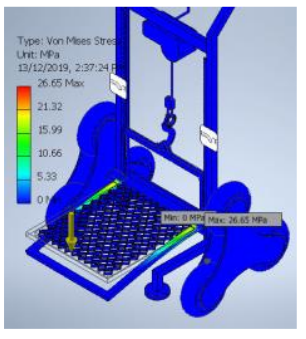

(a) Movable platform

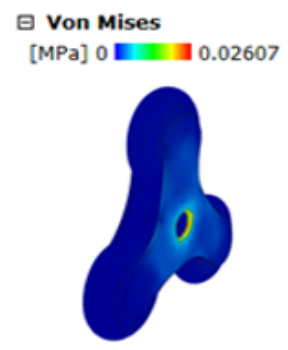

(c) Frame and wheel

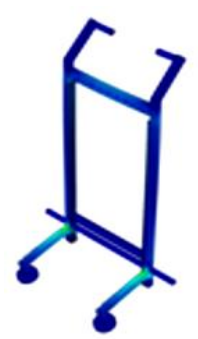

(b) Body

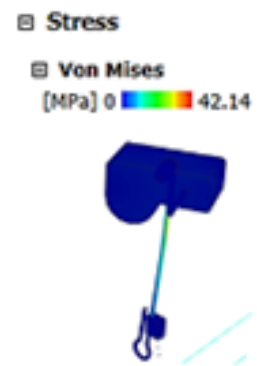

(d) Hand winch
Figure 5: Von Misses stress (MPa) analysis of the designed trolley

(ii) Displacement

Displacement is a location determination and part extension, which means how much force is needed to bend a component at a given distance or how far the object deforms [10]. The load of $200 \mathrm{~N}$ was applied in the simulation. This includes the consideration on the maximum load that can be exerted of the designed trolley is $20 \mathrm{~kg}$. For the displacement, the value obtained from simulation is $0.937 \mathrm{~mm}, 0.024 \mathrm{~mm}, 1.619 \times 10^{-6}$, and $1.653 \mathrm{~mm}$, respectively for the stockholder, the body, frame and wheel, and hand winch, as tabulated in Table 3. The displacement value which represents deformation must be well below $10 \mathrm{~mm}$ to indicate minimum bending of component or part. This indicates that the designed trolley will not experience deformation when loads of $20 \mathrm{~kg}$ are exerted on the designed trolley. The color contour plot of the displacement also shows how much the model has moved relative to its original position, as presented in Figure 6.

Table 2: Displacement on the components of tri-wheels stair climbing trolley

\begin{tabular}{|c|c|}
\hline Components & Displacement $(\mathrm{mm})$ \\
\hline Movable platform & 0.937 \\
\hline Body & 0.024 \\
\hline Frame \& wheel & $1.619 \times 10^{-6}$ \\
\hline Hand winch & 1.653 \\
\hline
\end{tabular}




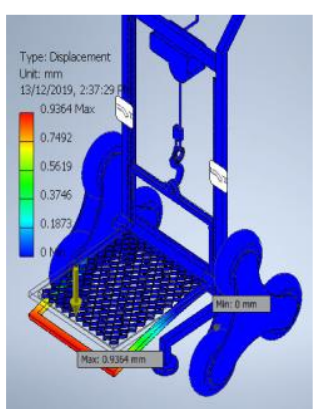

(a) Movable platform

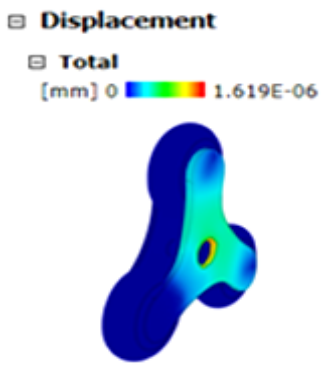

(c) Frame and wheel $\boxminus$ Displacement

日 Total

$[\mathrm{mm}] 0 \mathbf{0} 0.02407$

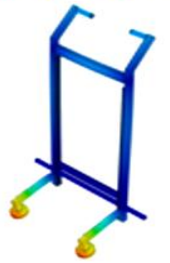

(b) Body

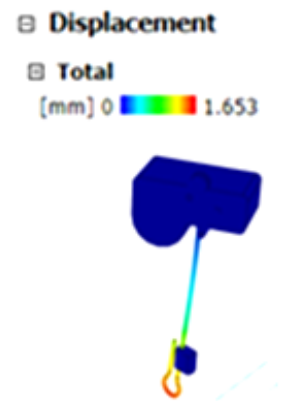

(d) Hand winch

Figure 6: Displacement (mm) analysis of the designed trolley

(iii) Strain

Strain is the measure of how much an object is stretched or deformed when forces are applied to an object, which deals with the change in length [11]. From the simulation analysis, the maximum equivalent strain obtained from the simulation is $1.072 \times 10^{-4} \mathrm{ul}, 3.064 \mathrm{x}$ $10^{-5} \mathrm{ul}, 2.942 \times 10^{-7}, 1.913 \times 10^{-4}$ respectively for the stockholder, the body, frame, and wheel, and hand winch, as tabulated in Table 3. The strain analysis of the designed trolley is presented in Figure 7.

Table 3: Strain on the components of tri-wheels stair climbing trolley

\begin{tabular}{|c|c|}
\hline Components & Equivalent strain $(\mathrm{ul})$ \\
\hline Movable platform & $1.072 \times 10^{-4}$ \\
\hline Body & $3.064 \times 10^{-5}$ \\
\hline Frame \& wheel & $2.942 \times 10^{-7}$ \\
\hline Hand winch & $1.913 \times 10^{-4}$ \\
\hline
\end{tabular}

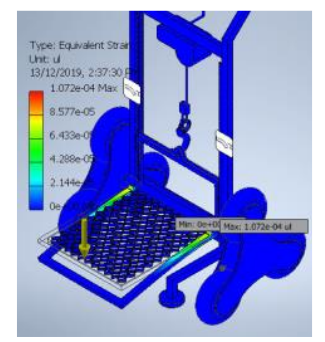

(a) Movable platform

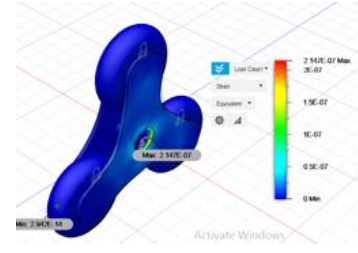

(c) Frame and wheel

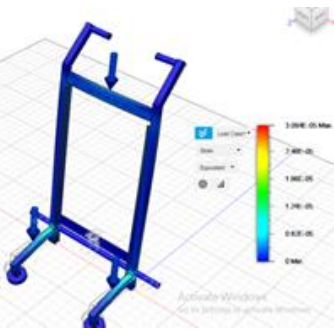

(b) Body

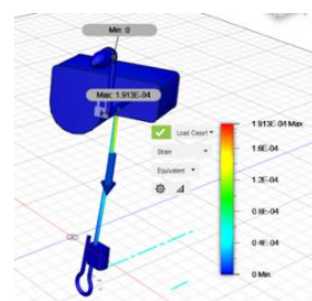

(d) Hand winch
Figure 7: Strain (ul) analysis of the designed trolley

(iv) Safety Factor

Safety factor evaluates the suitability of a design for its intended application (safe to be used, unharmed, bend, or break when subjected to the applied loads). Safety factors are expressed as the ratio of the maximum strength of the material (Yield or Ultimate Tensile Strength) to the actual stress in the part (Von Mises or 1st Principal Stress). By default, the maximum safety factor is $15 \mathrm{ul}$. The safety factor obtained is $7.77 \mathrm{ul}, 15$ ul, $15 \mathrm{ul}, 4.912 \mathrm{ul}$, respectively for the stockholder, the body, frame and wheel, and hand winch, as tabulated in Table 4 and presented in Figure 8. For the simulation analysis, the hand winch exerts the minimum value of safety factor, indicating that the hand winch is safe to be used to lift the loads. The lower is the safety factor, the safer is the product to the user.

Table 4: Safety factor on the components of tri-wheels stair climbing trolley

\begin{tabular}{|c|c|}
\hline Components & Safety factor (ul) \\
\hline Movable platform & 7.77 \\
\hline Body & 15 \\
\hline Frame \& wheel & 15 \\
\hline Hand winch & 4.912 \\
\hline
\end{tabular}



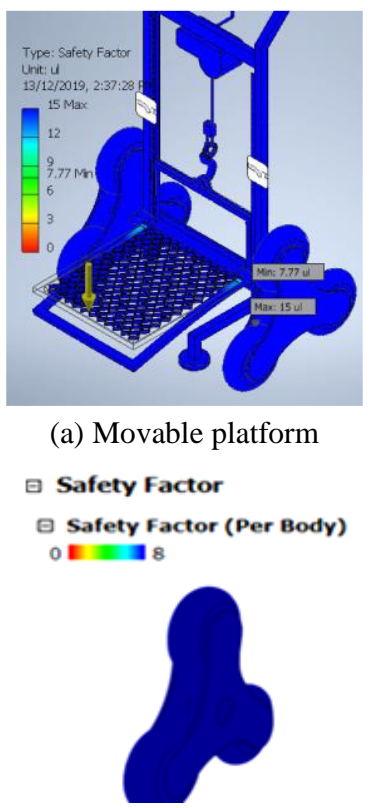

(c) Frame and wheel (a) Movable platform

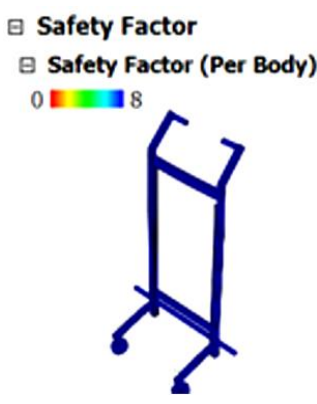

(b) Body

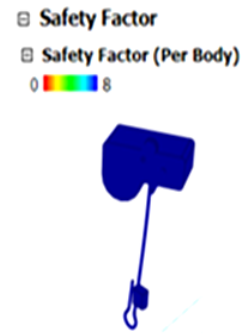

(d) Hand winch
Figure 8: Safety factor (ul) analysis of the designed trolley

\section{Physical Testing}

The simulation results obtained on the structural analysis of the designed trolley were confirmed by physical testing. The purpose of performing the physical test is to ensure the designed trolley can support $20 \mathrm{~kg}$ loads while climbing the stairs. The testing was conducted on the bottom floor staircase in the Faculty of Innovative Design and Technology building at Universiti Sultan Zainal Abidin. Each step has a height of $0.15 \mathrm{~m}$ and a depth of $0.3 \mathrm{~m}$ providing a slope of 30 degrees. $20 \mathrm{~kg}$ loads were applied on the trolley while climbing the stairs and the manual hand winch was used to lift them are shown in Figure 9.

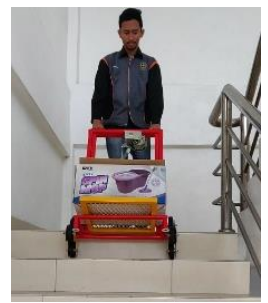

(a)

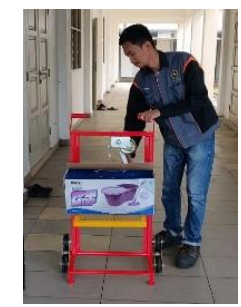

(b)
Figure 9: Physical testing of the designed trolley with loads $20 \mathrm{~kg}$

The designed trolley well functioned over the stairs with $20 \mathrm{~kg}$ loads applied to it. No bending or deformation was observed on the movable platform, body, frame, and wheel of the designed trolley, which further confirmed the simulation analysis result. The hand winch was also physically tested to lift the loads that were placed on the movable platform.

\section{CONCLUSION}

This work presents the design and development of trolleys for stairs climbing purposes. It provides effective stress distribution and enables the loadings without back pain problems. The quasi-planetary wheel frame gives a high performance to hold the wheels and climb the stairs easily. $20 \mathrm{~kg}$ of maximum loads can be lifted and carried by the trolley with the manual hand winch during testing. Mild steel was used as the material of this trolley because it is low cost, malleable, easy to fabricate, and joint together. For future improvement consideration on the developed trolley, the selection of material is a vital factor that should be considered to develop a lighter but tougher trolley. Material that is light but tough namely stainless steel is preferred to be used to develop a trolley that is lightweight but capable to support a heavier load. The stainless steel has corrosion and heat resistance, is very hygienic, is easy to machine, and is lighter than mild steel. This trolley also can improve with fully automated and robotic for climbing stairs.

\section{ACKNOWLEDGMENTS}

The authors acknowledge Universiti Sultan Zainal Abidin for equipment's support.

\section{REFERENCES}

[1] Hossain, A., Nafis, A., Rubaiat, I., and Shamiuzzaman, A. (2010). Design and Manufacturing of a Stair climbing Vehicle. International conference on industrial Engineering and Operations Management Dhaka.

[2] Sachin, S. L., Yashwantrao, B. P., Sawantwadi; Salave, N. V., Omkar, C. (2019). Design of Stair Climbing Trolley. Int. J. Sci. Res. Dev., 7(2): 907909.

[3] Mulik, S., Salunkhe R., Shaikh S., Waghmode D., and Swipnil G. (2016). Advance Material Handling Trolley using Tri-Wheel Mechanism. Int. J. Recent Res. Civ. Mech. Eng. IJRRCME, 2(2): 160-165.

[4] Vijay, R., Adesh, G., and Ranjit, D. (2018). "Design and Manufacturing of Stairclimbing Trolley," Int. J. Sci. Res. Sci. Eng., 7(3).

[5] Senthil K., Anoop, C.A., Anandhagobi, A, Dinakar., S. (2018). Design and Fabrication of Stair Climbing Trolley. International Research Journal of Engineering and Technology (IRJET), 5(3): 685-687. 
[6] Javidan, F., Heidarpour, A., Zhao, X.-L. and Minkkinen, J. (2016). Application of high strength and ultra-high strength steel tubes in long hybrid compressive members: experimental and numerical investigation. Thin-Walled Struct., 102: 273-285.

[7] Brockelsby, N. D. (1976). Pawl and ratchet construction for hand winch.

[8] Shrivastava, A., Krones, M., Pfefferkorn F. E. (2015). Comparison of energy consumption and environmental impact of friction stir welding and gas metal arc welding for aluminum. CIRP J. Manuf. Sci. Technol., 9: 159-168.
[9] Lothar, T. (2021). Failure Analysis and Prevention (2021 Edition). ASM International, 11. DOI:https://doi.org/10.31399/asm.hb.v11.a00067 79.

[10] Jang, H. L., Han, D. H., Hwang, M. Y., Kang, D., \& Kang, L. H. (2020). Displacement, Strain and Failure Estimation for Multi-Material Structure Using the Displacement-Strain Transformation Matrix. Materials (Basel, Switzerland), 13(1), 190. https://doi.org/10.3390/ma13010190

[11] Brinson, H.F., Brinson, L. C. (2008). Polymer Engineering Science and Viscoelasticity: An Introduction. Springer, XVI:448, DOI: https://doi.org/10.1007/978-0-387-73861-1 